\title{
Thermodynamic Simulation and Experimental Investigation of Plasma Preparation of Nanosized Carbon Using Propane
}

\author{
Zuyun Luo $\mathbb{D}^{1,2}$ Fangfang Wang, ${ }^{1}$ Jinjia $X{ }^{1,3}{ }^{1,3}$ Jieying Liu, ${ }^{1}$ and Ruoyu Hong $\mathbb{D}^{1}$ \\ ${ }^{1}$ School of Chemical Engineering, Fuzhou University, Fuzhou 350116, China \\ ${ }^{2}$ School of Zhicheng, Fuzhou University, Fuzhou 350002, China \\ ${ }^{3}$ Weldon School of Biomedical Engineering, Purdue University, West Lafayette, IN 47907, USA
}

Correspondence should be addressed to Ruoyu Hong; rhong@fzu.edu.cn

Received 12 December 2018; Accepted 21 February 2019; Published 17 April 2019

Academic Editor: Ilaria Armentano

Copyright (c) 2019 Zuyun Luo et al. This is an open access article distributed under the Creative Commons Attribution License, which permits unrestricted use, distribution, and reproduction in any medium, provided the original work is properly cited.

\begin{abstract}
Carbon black was prepared by pyrolysis of propane under different plasma conditions. The effects of the flow ratio of the carbon precursor, discharge current, and plasma gases (including argon, nitrogen, and hydrogen) on the morphology and structure of carbon black were investigated by a series of physical characterizations. The equilibrium components were computed based on the minimization of the Gibbs free energy. The theoretical analysis and experimental results confirmed that HCN is the inevitable byproduct in the tail gas from the nitrogen plasma process, indicating that nitrogen is inappropriate as the carrier gas for the preparation of carbon black. The effects of discharging current, discharging spacing, and proportions of propane were also symmetrically studied by the evaluation of HCN concentration. Moreover, the graphene was generated when using argon as the plasma gas mixed with a small amount of hydrogen.
\end{abstract}

\section{Introduction}

Carbon black is one of the most commonly used carbon nanomaterials and has nowadays been widely applied as electrically conductive materials and reinforcing fillers in the areas of rubbers, plastics, elastomers, and batteries due to its peculiar and tunable chemical, physical, and electrical properties [1-6].

The different kinds of carbon black are generally manufactured by calcination in furnace, channel and lamp processes, thermal pyrolysis, or acetylene method [7]. These processes are usually categorized into incomplete combustion and thermal decomposition of hydrocarbon, depending on the participation of oxygen [8]. Although more than $95 \%$ of carbon black products are fabricated by furnace and channel processes, the increasing environmental issues and pollution emission caused by these mainstream approaches cause serious human health problems. Thus, alternative and sustainable technologies are highly desirable for the preparation of carbon black [9].
The plasma processes have gained increasing attention in the development of a renewable method to overcome these drawbacks during the existing processes. Considered as the fourth state of matter apart from solid, liquid, and gas, plasma usually consists of molecules, atoms, ions, electrons, and radicals [10]. Plasma could be obtained via various methods, such as combustion, flame technique, electrical heating, and electrical discharge [11]. Researchers have developed several plasma processes such as plasmatron [12], dielectric barrier discharge [13], gliding arc discharge $[14,15]$, corona technique [16], microwave method [17-19], pulse discharge [20], and direct current discharge [21]. Considering its energy level, temperature, and electronic density during the discharging process, plasma is categorized as thermal and nonthermal [22] ones. The temperatures of electrons in nonthermal plasma can reach the range from 10000 to $100000 \mathrm{~K}$, while the gas temperature remains as low as room temperature. This high electron temperature leads to the unusual chemical and physical properties of nonthermal plasma. However, in the thermal 
plasma, the temperatures of electron and ambient gas are considered to be close to each other. Therefore, thermal plasma exhibits higher chemical reactivity than the nonthermal one.

Thermal plasma technology was initially investigated in the early times of the twentieth century and has been extensively studied thereafter. Plasma preparation of carbon black was first demonstrated by Rose [23] in 1920. In his work, electrodes were installed on the ends of a cylindrical reactor and carbon black was prepared through pyrolysis of hydrocarbon. Later on, Ryan [24] put different hydrocarbons into the same plasma reactor and found that the prepared carbon black showed semblable properties. This finding also confirmed the feasible preparation of carbon black by plasma. Thus, research on the plasma preparation of carbon black has focused on optimizing technological process and reaction conditions.

The thermal plasma technology has attracted much interest recently mainly because of its potential in the largescale production of carbon black through the pyrolysis of hydrocarbon. This technology obviates harsh conditions such as acid, base, or catalysts, thereby being considered to be easily controllable and environmentally friendly.

The pyrolysis of hydrocarbon by thermal plasma is a complex and dynamic process. In a closed system, the conversion reaction among components will reach equilibrium after a certain period of time. The principle of computing the equilibrium composition is mainly thermodynamics. The thermodynamics deals only with the problem of equilibrium, not the equilibrium reaction rate. Although there are few phenomena indicating that the process is completely under equilibrium, it is still important to study the equilibrium process. First, the equilibrium determines the limitation that the given reaction can be achieved. Second, the equilibrium predicts the changing trend of product composition as the reaction conditions (temperature, pressure, etc.) change and provides the processing conditions for the desirable products [25-28].

Argon and helium are the most commonly used carrier gas to generate ambient plasma [29-32] because these monatomic gases are inert and easily maintain ambient plasma. However, argon and helium are expensive and unsuitable for large-scale manufacturing of carbon black. The preparation of carbon black using nitrogen plasma shows great advantages in terms of cost control, because nitrogen is relatively cheap and easy to ignite at atmospheric pressure.

In this study, carbon black is prepared by the thermal pyrolysis of propane using argon, hydrogen, and nitrogen as carrier gases. The essential properties of carbon black prepared through different processes were analyzed in both theoretical and experimental ways. Besides, the equilibrium compositions were obtained by the minimization of Gibbs free energy. It was found that HCN has been identified as the byproduct while using nitrogen as the carrier gas. The optimal conditions for reducing the concentration of $\mathrm{HCN}$ in the tail gas were also explored.

\section{Materials and Methods}

2.1. Materials and Devices. The reactor system in this study was designed based on the preliminary research of Zhao et al. [33]. As shown in Figure 1, this system consists of a power source, a plasma generator, a heat exchanger, and an $\mathrm{HCN}$ absorber. In the experimental conditions, propane and carrier gas were mixed in the buffer tank and flowed into the plasma reactor. The propane was decomposed into carbon black and hydrogen in the plasma environment. The gas-solid mixtures passed through the heat exchanger, and the obtained carbon black was filtered by the sintered disc. In order to determine the HCN concentration, the tail gas was collected and tested.

Propane $\left(\mathrm{C}_{3} \mathrm{H}_{8}\right)$, nitrogen $\left(\mathrm{N}_{2}\right)$, argon (Ar), and hydrogen $\left(\mathrm{H}_{2}\right)$ were all industrial grade and purchased from Suzhou Jinhong Gas Co. Ltd. The sodium hydroxide $(\mathrm{NaOH})$ and acetone $\left(\mathrm{CH}_{3} \mathrm{COCH}_{3}\right)$ were obtained from Sinopharm Chemical Reagent Co. Ltd. Rhodanine $\left(\mathrm{C}_{12} \mathrm{H}_{12} \mathrm{~N}_{2} \mathrm{OS}_{2}\right)$ and silver nitrate $\left(\mathrm{AgNO}_{3}\right)$ were provided by Shanghai Jinchun Biological Tech. Co. Ltd.

2.2. Preparation of Carbon Black. The thermal plasma was produced by an electric arc between tungsten electrodes connected to an AC power supply. The reactor was first purged with the carrier gas. Then, propane was poured in and the AC power was turned on. Discharging was maintained for 10 minutes to allow us to examine the experimental results. A rubber tube was connected to the end of the condenser, and the gas flowed out of the plasma zone was blown into the sodium hydroxide solution and the HCN was absorbed to obtain a sample solution. The sample solution was added with rhodanine and titrated by silver nitrate solution. When the color of the solution changed from yellow to orange, the titration reached the end point. The concentration of $\mathrm{CN}^{-}$was calculated according to the dosage of the silver nitrate solution using the following formula:

$$
\begin{aligned}
\mathrm{c}\left(\mathrm{CN}^{-}\right)(\mathrm{mg} / \mathrm{mL})= & 1.04(\mathrm{mg} / \mathrm{mL}) \\
& \times \frac{\text { silver nitrate solution dosage }(\mathrm{mL})}{10(\mathrm{~mL})} .
\end{aligned}
$$

The concentration changes of $\mathrm{CN}^{-}$in the plasma system were determined and compared by changing the current and distance between electrodes and the propane flow ratio.

\section{Results and Discussion}

\subsection{Single Factor Analysis for the Morphology of Carbon Black}

3.1.1. Effect of Propane Flow Ratio. To examine the effect of the propane flow ratio on the morphology of the carbon black, the reaction was performed using tungsten electrode with a total gas flow of $1.5 \mathrm{~m}^{3} / \mathrm{h}\left(\mathrm{N}_{2}\right.$ as the carrier gas) and the propane flow ratio regulated at $10 \%, 20 \%, 30 \%$, and $40 \%$. Figure 2 shows the SEM images of carbon black 


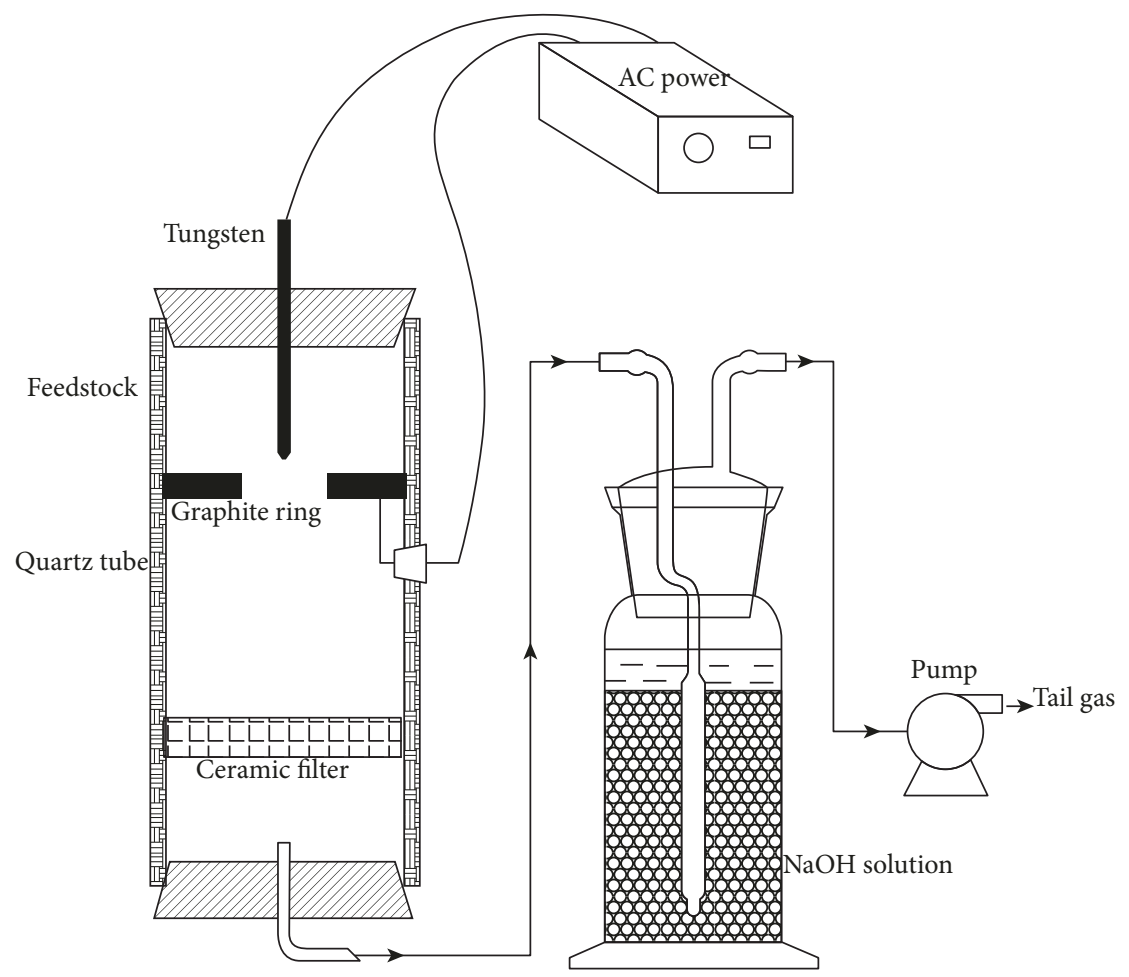

Figure 1: Schematic diagram of an AC arc plasma reactor system.

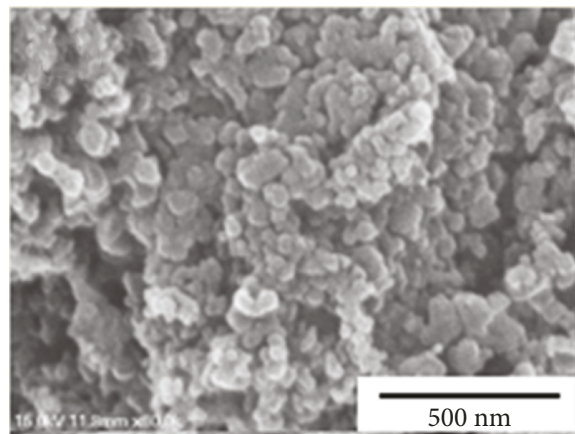

(a)

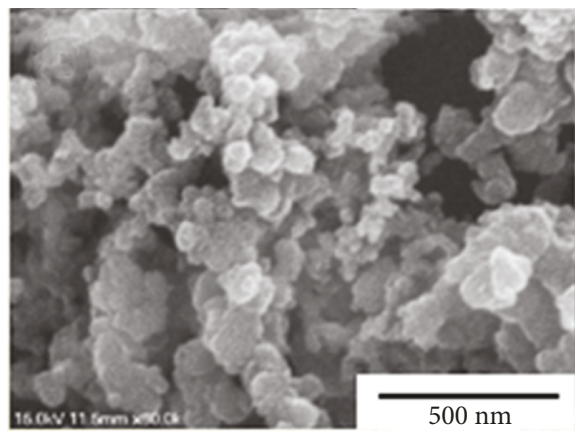

(c)

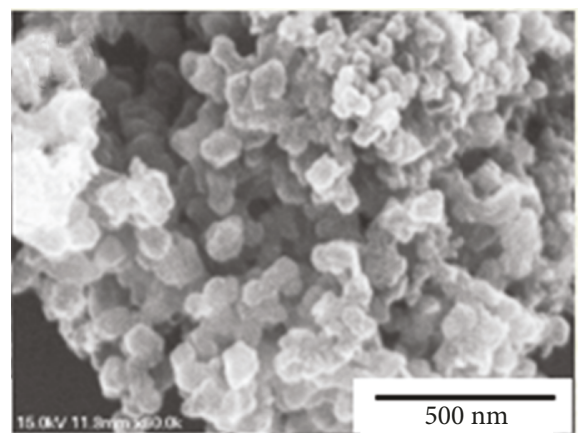

(b)

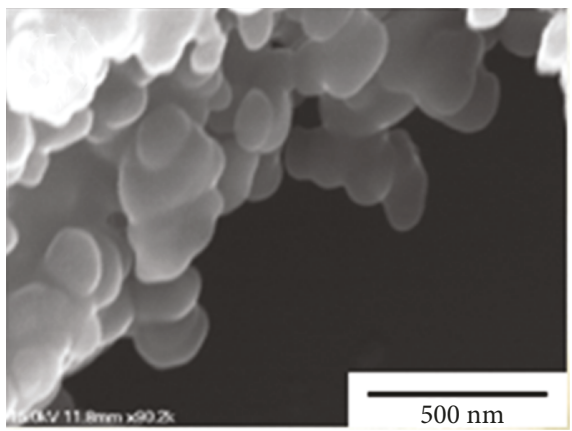

(d)

FIGURE 2: SEM images of carbon black prepared under different percentages of propane flow: (a) 10\%, (b) 20\%, (c) $30 \%$, and (d) $40 \%$.

prepared at different propane flow ratios. With the same total flow ratio, the average particle size of carbon black increases along with the increasing propane flow ratio. At a low propane flow ratio of $10 \%$, the obtained carbon black exhibits good dispersibility with an average diameter of $30-40 \mathrm{~nm}$ as shown in Figure 2(a). When the propane flow ratio increased 
to $20 \%$, it was obvious that the particle size of carbon black increased to $60-70 \mathrm{~nm}$ (Figure 2(b)) with relatively good dispersion. While further increasing the propane flow ratio to $30 \%$, the carbon black shows agglomeration (Figure 2(c)). The higher propane flow ratio in the mixed gases leads to a higher nucleation rate and the formation of smaller subparticles within a short time. Subsequently, these small subparticles aggregated to form a large nanostructure. Figure 2(d) shows that a lot of carbon black generated by plasma was aggregated to form large spherical carbon black when the propane flow ratio is $40 \%$. That is, the larger the propane flow ratio in the mixed gases, the higher the amount of carbon black prepared by the plasma [34]. These particles go through a microcosmic random walk and become interconnected in different directions. It is assumed that carbon black possibly agglomerated to a spherical structure according to the results shown in Figure 2(d). Therefore, a 20\% propane flow ratio is the optimal condition for the preparation of carbon black.

Figure 3 shows the X-ray diffraction (XRD) patterns of carbon black prepared under different propane flow ratios. It is observed that all the samples have remarkable (002) and (100) peaks with corresponding $2 \theta$ of $24^{\circ}$ and $44^{\circ}$, respectively. The (002) peak represents the graphitized structure, and a higher and narrower peak indicates the higher graphitization of carbon black [35]. The (100) peak indicates that the $\mathrm{CB}$ possessed a disordered structure. The XRD curves of four samples indicate that $d_{002}$ increases and $L_{002}$ decreases with increasing propane flow ratios, and the (100) peak has no significant change when the flow ratio of propane is greater than $10 \%$. This finding indicates a decrease in the graphitization of carbon black. Therefore, reducing the propane concentration can increase the graphitization of carbon black.

3.1.2. Effect of the AC Current. The reaction was performed using a tungsten electrode with an AC current of 2-8 A to determine the effect of the AC current on the morphology of the carbon black. The TEM images of carbon black prepared at different currents are shown in Figure 4. The average size of carbon black increases along with the increasing current. As shown in Figure 4(a), the clear outline of carbon black particles was seen for an AC current of $2 \mathrm{~A}$. When the current increased to $4 \mathrm{~A}$, it was found that the particles of carbon black started to agglomerate, but the basic appearance of carbon black particles can still be observed in Figure 4(b). As the current continues to increase, the severe agglomeration of carbon black particles can be observed obviously in Figures 4(c) and 4(d). It is suggested that the plasma temperature and growth rate of carbon black particles are influenced by the increase of the input current. According to the previous studies, the plasma gas temperature increases along with increasing energy input [36]. Thus, the corresponding plasma gas temperature increases when the $\mathrm{AC}$ current is increased from 2 to $8 \mathrm{~A}$. Usually, a higher power enhances the endothermic decomposition of propane, leading to higher temperature and greater nonequilibrium driving force for the growth of carbon black. This result might be explained by the fact that the particle growth rate

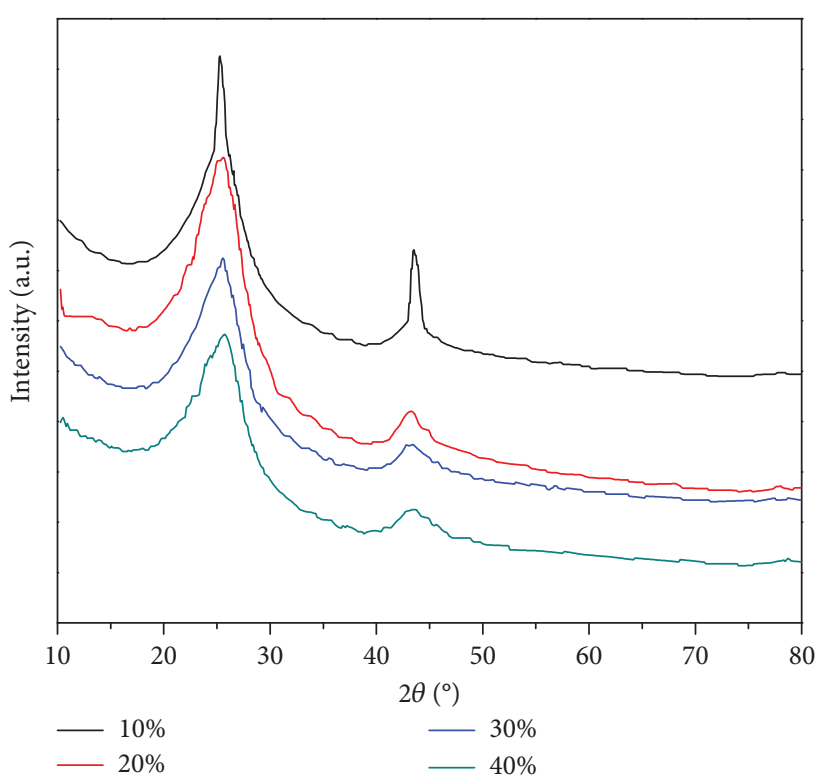

FIGURE 3: XRD patterns of carbon black prepared under different propane flow percentages: $10 \%, 20 \%, 30 \%$, and $40 \%$.

is more rapid than the nucleation rate at high reaction temperatures, which resulted in the production of particles with a larger size.

The Raman spectra of carbon black at different AC currents are shown in Figure 5. The carbon black exhibits intense $D$ and $G$ peaks at around $1330 \mathrm{~cm}^{-1}$ and $1580 \mathrm{~cm}^{-1}$, respectively. These peaks originate from the growth of carbon crystallites in size and number, leading to the formation of a partially ordered structure. This finding indicates the disordered random orientation of the tubes and the graphitic nature of the carbon materials [37], respectively. Cho et al. [38] reported that the partial ordering of amorphous carbon at high temperatures resulted in the appearance of intense $D$ and $G$ peaks in the Raman spectrum. The ratio of $D$ and $G$ peaks $\left(I_{D} / I_{G}\right)$ determines the amount of disorder in the crystallinity [39]. The larger the ratio of $I_{D} / I_{G}$, the lower the graphitization of carbon black that could be observed. The growth from amorphous carbon to nanocrystalline carbon generates a temperature increase from 1700 to $2000 \mathrm{~K}$ [40]. As shown in Figure 5, with the AC current increasing, the value of $I_{D} / I_{G}$ decreases and the graphitized degree of the carbon black increases. Therefore, increasing the AC current is conducive for the formation of an ordered high-graphitized carbon black structure [41].

3.1.3. Effect of the Different Types of Carrier Gases. To find out suitability of carrier gases, different carrier gases have been tested, and the morphology of carbon black must be investigated to determine which carrier gas is the most suitable.

Figure 6 shows the SEM images of carbon black prepared by a plasma process using different carrier gases. The figure depicted that carbon black prepared using argon plasma exhibits the biggest particle size of $120 \mathrm{~nm}$ (Figure 6(a)). Compared with argon, nitrogen as a kind of diatomic gas needs more energy to break its $\mathrm{N} \equiv \mathrm{N}$ bond. Thus, during 


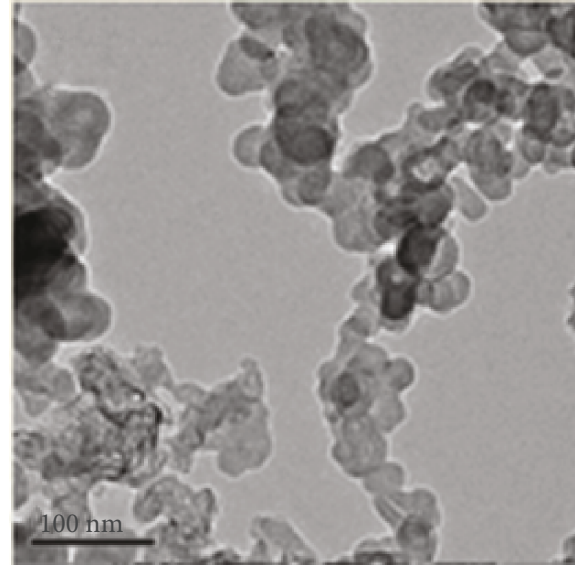

(a)

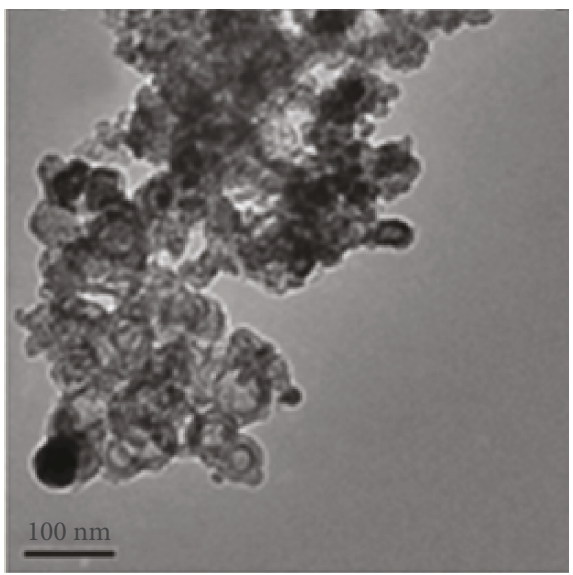

(c)

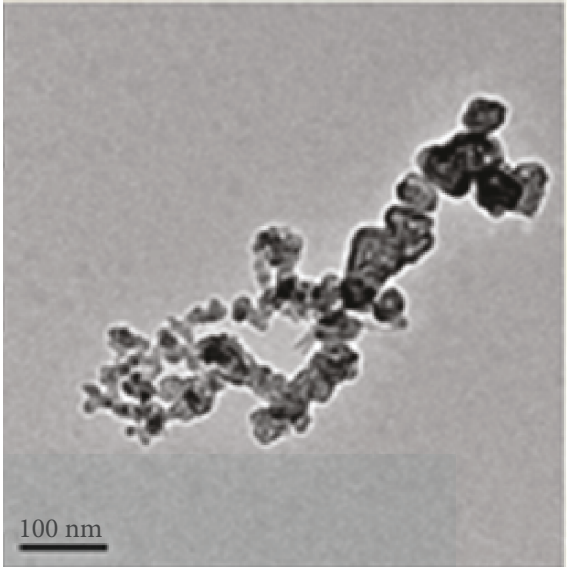

(b)

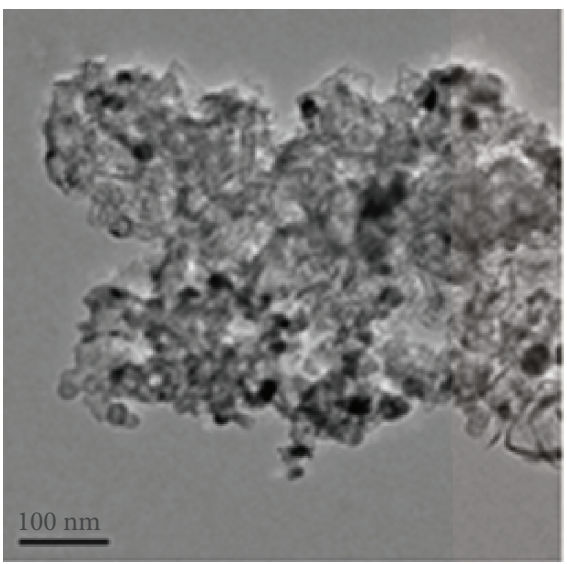

(d)

Figure 4: TEM images of carbon black prepared at different AC currents: (a) $2 \mathrm{~A}$, (b) $4 \mathrm{~A}$, (c) $6 \mathrm{~A}$, and (d) $8 \mathrm{~A}$.

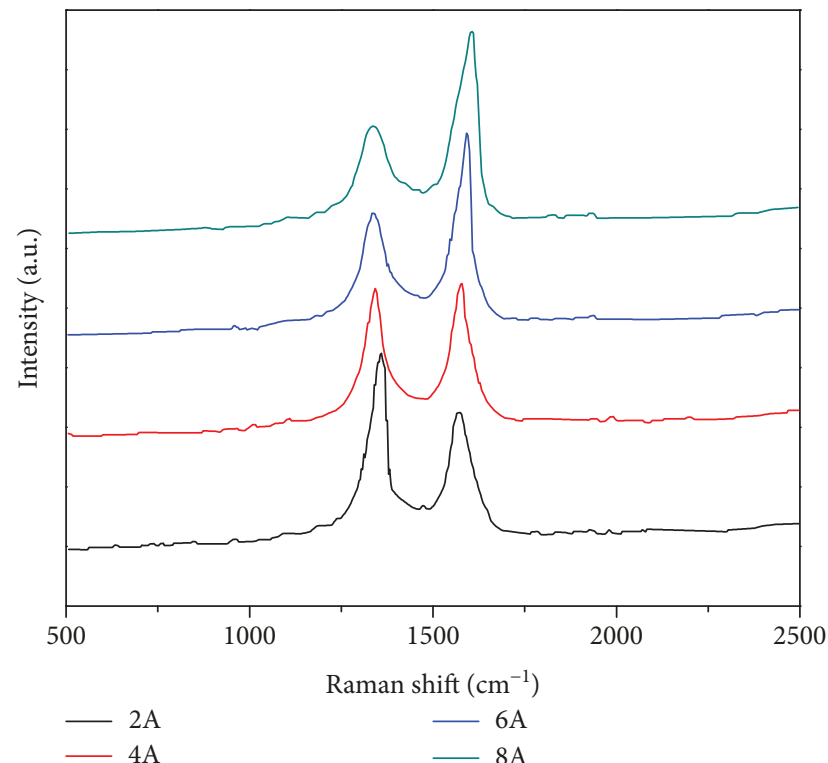

FIGURE 5: Raman spectra of carbon black prepared at different AC currents: $2 \mathrm{~A}, 4 \mathrm{~A}, 6 \mathrm{~A}$, and $8 \mathrm{~A}$. the discharging process, nitrogen uptakes more energy to form a plasma environment, which competes with the growth rate of carbon black.

The particle size from the nitrogen plasma is generally in the range of 80 to $100 \mathrm{~nm}$ (Figure 6(b)). Figure 6(c) reveals that carbon black from hydrogen plasma is around $50 \mathrm{~nm}$, which is the smallest size among the three kinds of carrier gases. This is due to the hydrogen needing more energy than the nitrogen and argon to form plasma. The hydrogen radicals with ultrahigh activity generated during the discharging process bind to the carbon atoms at the outer surface of carbon black and were released in the form of hydrocarbon [42] during the growth process.

For further observations of the morphological and branching structure of carbon black products, the TEM measurements were conducted (Figure 7). As depicted from the TEM images, the carbon black prepared from argon plasma shows the homogeneous distribution of the primary particle size but aggregates more severely than those prepared from nitrogen and hydrogen plasma. The nonuniformity in the size of carbon black from nitrogen plasma is evident from the observation shown in Figure 7(b). This nonuniformity is possibly caused by the adsorption of energy 


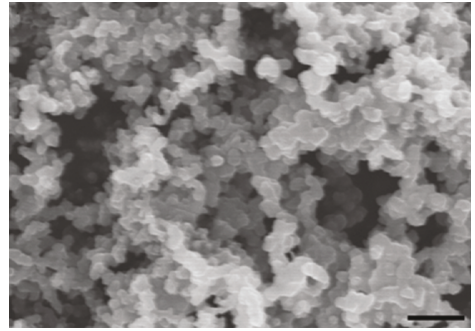

(a)

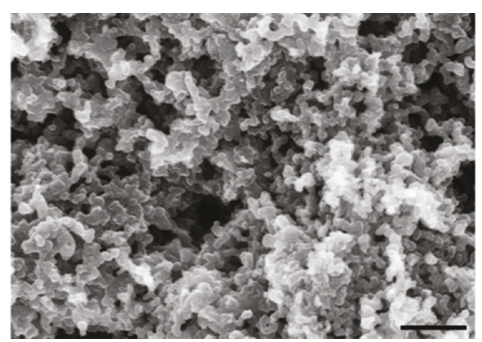

(b)

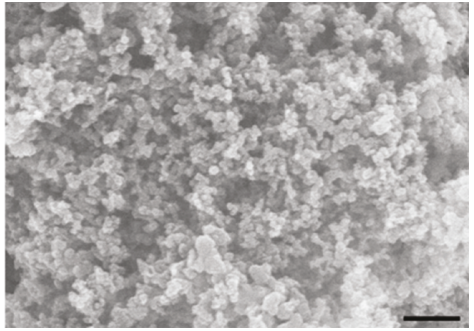

(c)

FIGURE 6: SEM of carbon black prepared under different plasma gases: (a) argon, (b) nitrogen, and (c) hydrogen. All the scale bars are $1 \mu \mathrm{m}$.

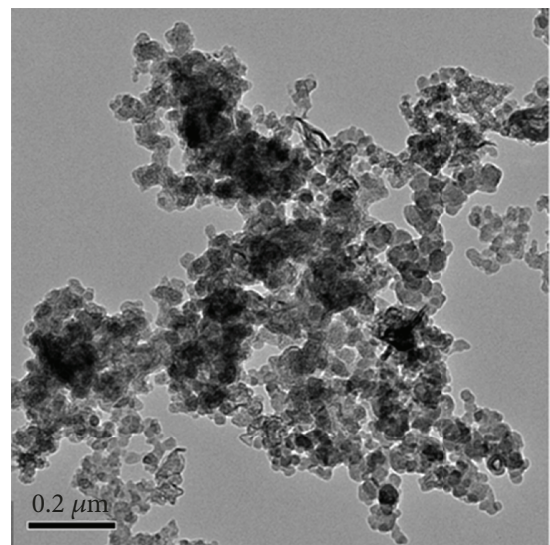

(a)

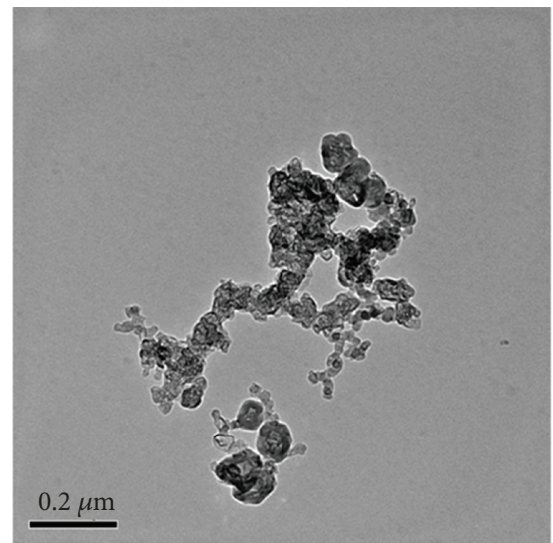

(b)

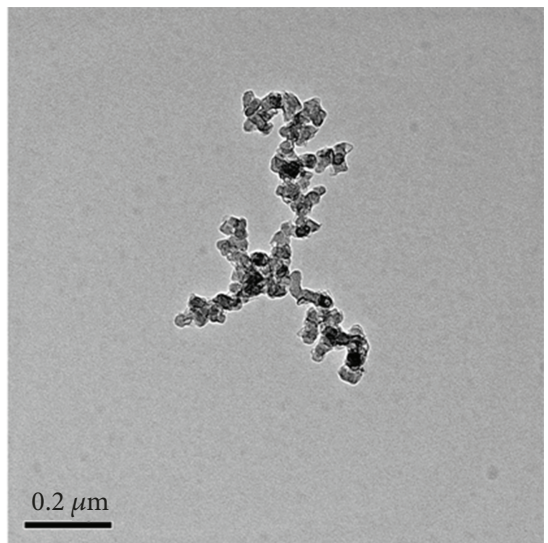

(c)

FIGURE 7: TEM morphology of carbon black prepared under different plasma gases: (a) argon, (b) nitrogen, and (c) hydrogen.

to break a $\mathrm{N} \equiv \mathrm{N}$ bond, which brings a relatively intense temperature gradient in the plasma environment. In the high-temperature area, the carbon black particles grow in a sufficiently fast rate, while the growth rate is limited in the low-temperature area.

3.2. Structures of Carbon Black. The critical structures of carbon black were characterized by XRD and Raman spectroscopic analysis to determine the effect of plasma gas on the structure of carbon black. As shown in Figure 8, the peak corresponding to the (002) lattice plane around $26^{\circ}$ appears in all of the three patterns. For the carbon black prepared by hydrogen plasma, the (002) lattice plane is located at $25.9^{\circ}$ with a $d$-spacing of $0.352 \mathrm{~nm}$. The plane exhibits left skewing compared with the ideal graphite, which shows a sharp and intense peak at $26.5^{\circ}$ with a $d$-spacing of $0.334 \mathrm{~nm}$. This left skewing and the enlargement of interlamellar spacing indicate the existence of amorphous carbon and distortion of lattice fringes [28]. The (002) peak of carbon black obtained from nitrogen plasma is located at $26.1^{\circ}$ with a $d$-spacing of $0.349 \mathrm{~nm}$. The carbon black obtained from argon plasma shows a wide (002) peak with a low intensity at $25.5^{\circ}$ and $d$-spacing of $0.356 \mathrm{~nm}$. Based on this information, the crystalline structure of carbon black from nitrogen plasma is the best among the three samples. The Raman spectroscopic analysis was carried out to verify this result.

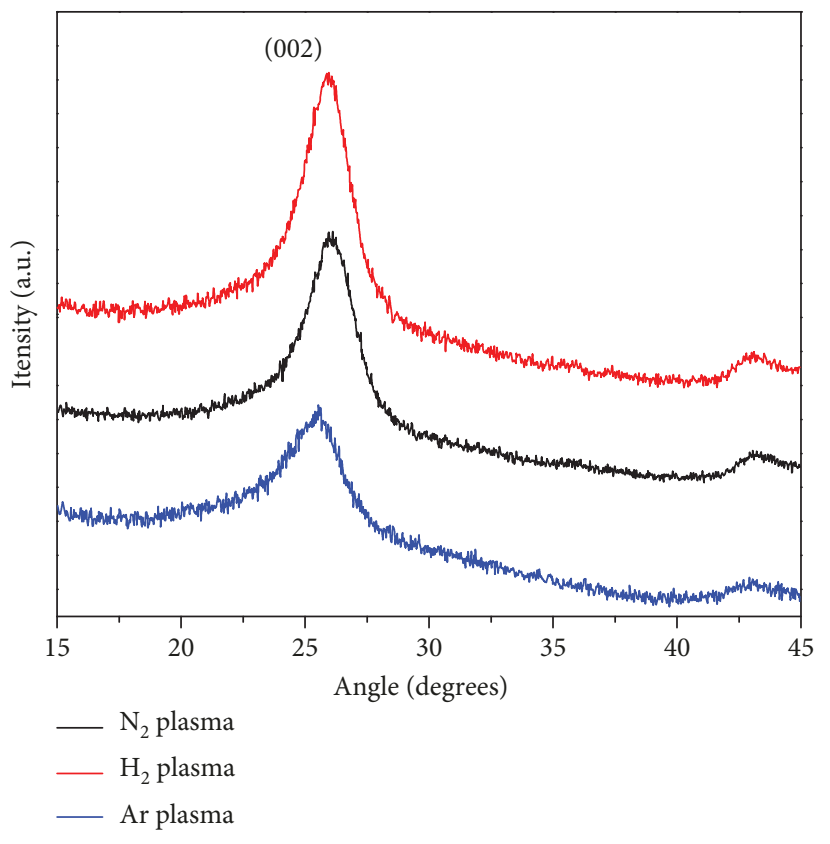

FIGURE 8: XRD patterns of carbon black prepared under different plasma gases. 
The Raman spectroscopy can effectively characterize the structure of carbon nanomaterials. Generally, the two pattern peaks of carbon black in the Raman spectra are as follows: the $D$ band around $1330 \mathrm{~cm}^{-1}$ is assigned to the disorder and defects in carbon black and the $G$ band around $1580 \mathrm{~cm}^{-1}$ is due to the well-ordered lattice plane $[43,44]$. The intensity ratio between the $D$ band and the $G$ band $\left(I_{D} / I_{G}\right)$ is a significant index used to estimate the quality of carbon black. As shown in Figure 9, the $I_{D} / I_{G}$ ratio of carbon black prepared from argon plasma exhibits the highest value of 1.33. This finding is probably because in the argon plasma, a large amount of amorphous carbon was deposited onto the surface of carbon black, leading to larger defects and bigger particle size. The $I_{D} / I_{G}$ ratio of carbon black from hydrogen plasma is lower; it is because of active hydrogen radicals etching the amorphous carbon during the growth process. The $I_{D} / I_{G}$ ratio of carbon black prepared from nitrogen plasma is 0.99 , which is the lowest among the three kinds of carbon black and indicates the best quality. This result is consistent with the XRD results.

3.3. Thermal Stability of Carbon Black. The thermogravimetric analysis (TGA) was conducted to investigate the thermal stability of carbon black prepared by different processes. This analysis can estimate the surface cleanliness of carbon black to indirectly assess the quality and secondary structure. As shown in Figure 10, the carbon black prepared by argon plasma degraded faster than other samples due to the volatilization of amorphous carbon with $73.5 \%$ residual at $1000^{\circ} \mathrm{C}$. The carbon black prepared by nitrogen plasma is more stable than that prepared by argon plasma due to less amorphous carbon with $84.2 \%$ residual at $1000^{\circ} \mathrm{C}$. However, the carbon black from nitrogen plasma shows a higher amount of surface functional groups than that from hydrogen plasma which is theoretically recognized to have a totally clean surface with little amorphous carbon black. Hence, the carbon black from hydrogen plasma is more stable and maintains $88.9 \%$ residual at $1000^{\circ} \mathrm{C}$. As shown in the TGA curves, all three kinds of samples exhibit obvious weight loss before $200^{\circ} \mathrm{C}$. The highest weight loss was found in carbon black from argon plasma. This phenomenon could be explained by TEM observation of its structure. It is well known that carbon black exhibits hygroscopicity, developed secondary structure, and high water absorbing capacity. In Figure 7(a), the carbon black prepared from argon plasma possesses a more organized secondary structure owing to more chains. Therefore, a higher amount of water vapor was adsorbed by the carbon black from argon plasma when stored in air, leading to a dramatic weight loss during the thermogravimetric process. As shown in Figure 7(c), carbon black prepared by hydrogen plasma is less branched with lower water absorbing capacity and thus exhibits the highest thermal stability before $200^{\circ} \mathrm{C}$.

3.4. The Formation of Cyanide. The equilibrium components of $1 \mathrm{~mol}$ propane after pyrolysis under different kinds of plasma are shown in Figures 11, 12, and 13. The simulation was carried out using FactSage software [45]. Generally, the components show similar varying trends under all

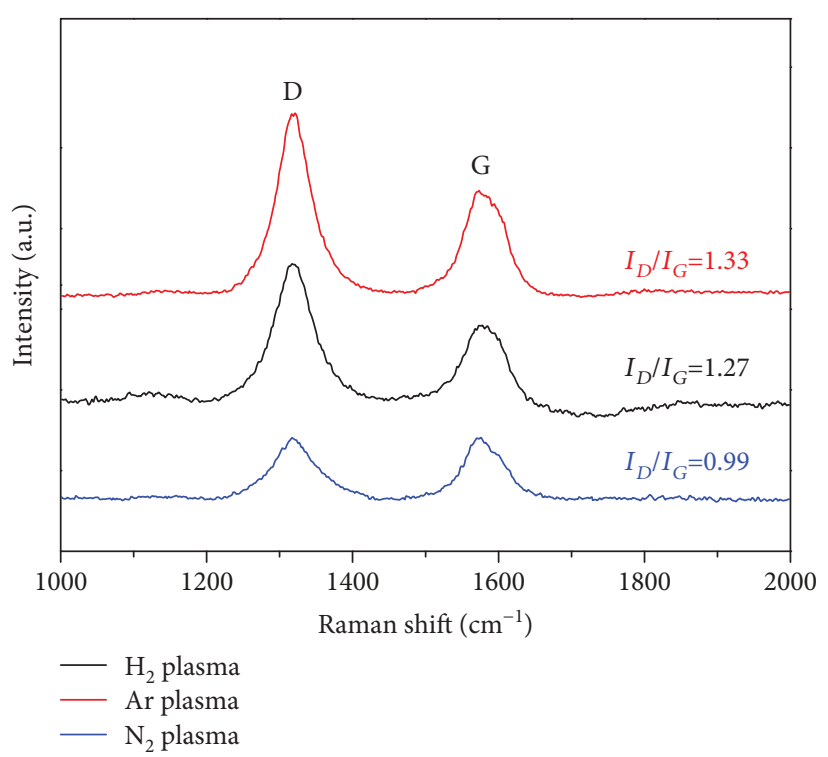

FIGURE 9: Raman spectra of carbon black prepared under different plasma gases.

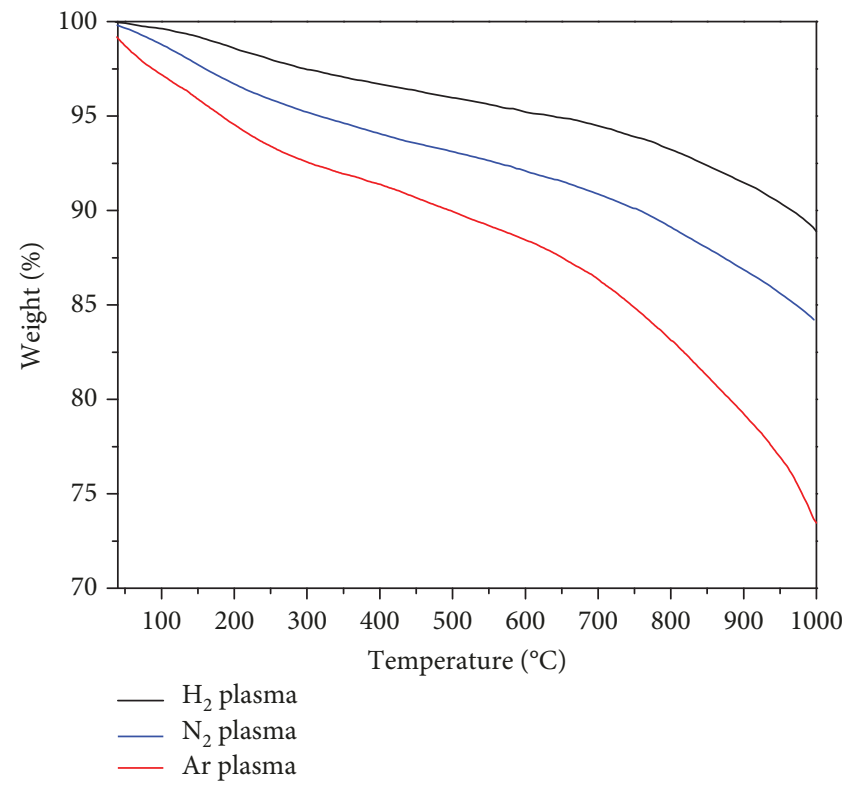

FIGURE 10: TGA curves of the as-prepared three kinds of carbon black.

circumstances. It is noticeable that propane is first decomposed into methane and ethane and then further polymerized to form polycyclic aromatic hydrocarbon, which becomes the primary nuclei of carbon black [28]. The propane could be totally pyrolyzed before $800^{\circ} \mathrm{C}$ in the argon (Figure 14) and nitrogen (Figure 15) plasma and at $1200^{\circ} \mathrm{C}$ in the hydrogen (Figure 11) plasma. This phenomenon could be attributed to the fact that high hydrogen concentration would hinder the decomposition of propane into methyl and hydrogen radicals. Although previous works reported that HCN cannot be generated using nitrogen as plasma gas [46], the 


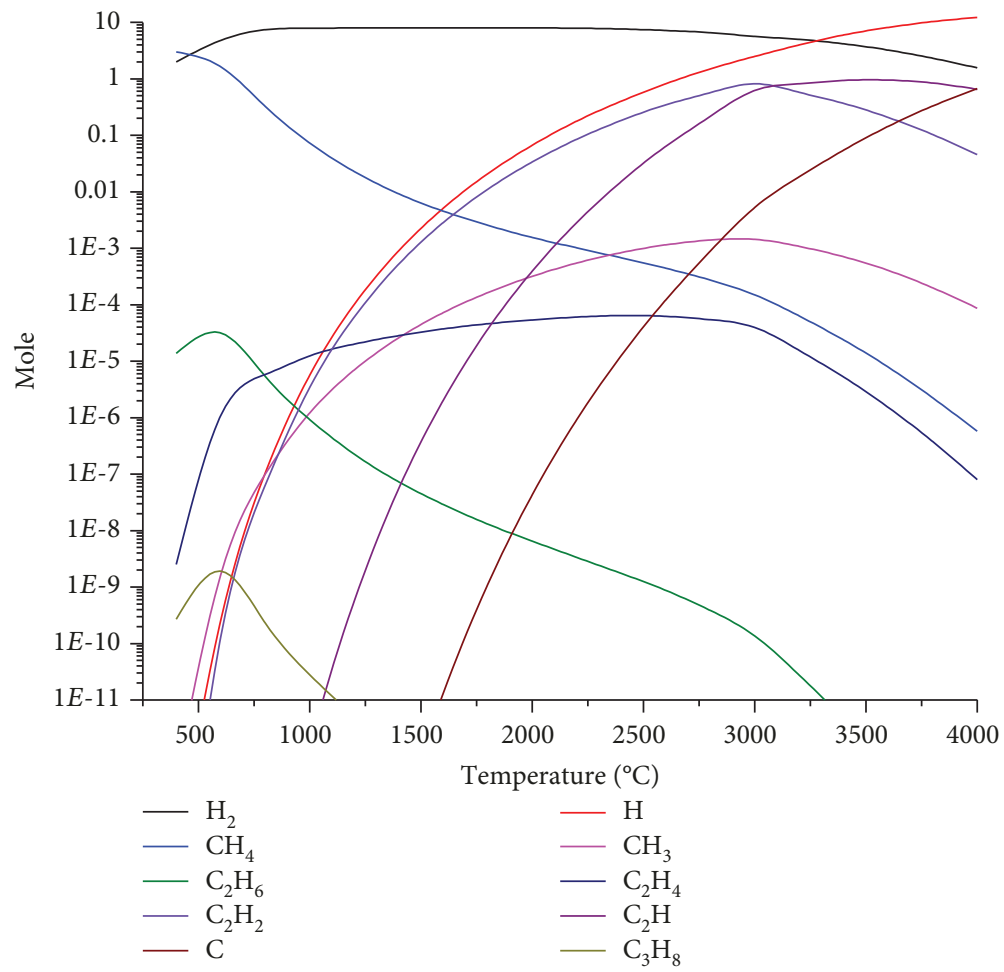

FIgURE 11: Simulated components of 1 mol propane after pyrolysis in hydrogen under thermodynamic equilibrium.

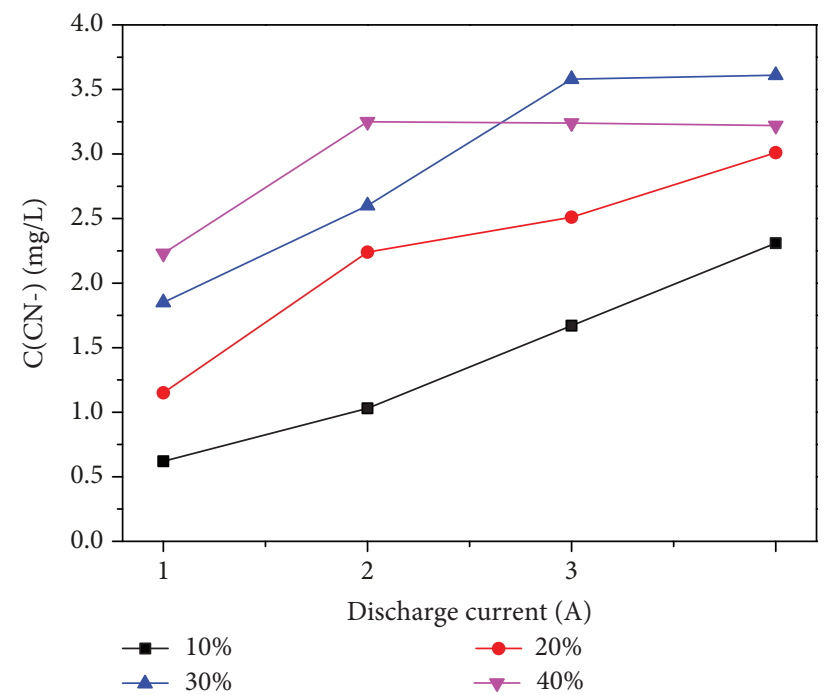

Figure 12: $\mathrm{C}\left(\mathrm{CN}^{-}\right)$detected in absorption liquid under different discharge currents and gas flow rates using nitrogen.

thermodynamic equilibrium simulation showed that $\mathrm{HCN}$ is one of the major components in the equilibrium system while using nitrogen as the carrier gas. The concentration of HCN increases significantly along with the increasing of temperature.

To verify the simulation results, experiments were carried out by changing the electric current $(1,2,3$, and $4 \mathrm{~A})$ and propane flow percentage $(10 \%, 20 \%, 30 \%$, and $40 \%$; total flow $120 \mathrm{~L} / \mathrm{h}$ ) to demonstrate whether cyanide was generated. The

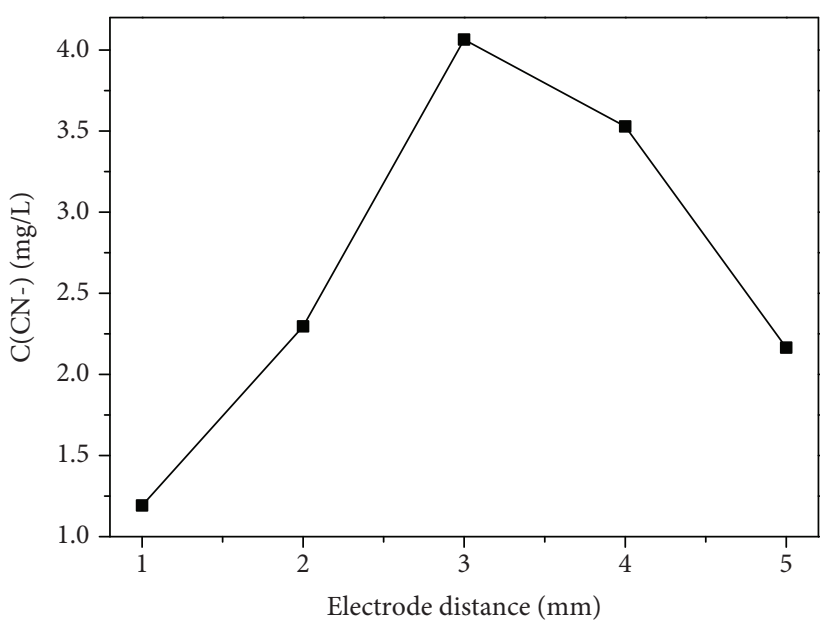

Figure 13: $\mathrm{C}\left(\mathrm{CN}^{-}\right)$detected in absorption liquid under different electrode distances using nitrogen.

HCN concentration was then measured in the tail gases. Figure 12 shows the concentration of HCN under the experimental conditions. In contrast to previous reports, $\mathrm{HCN}$ was formed using nitrogen as plasma gas. In general, the concentration of HCN increases with the increasing of current or propane flow percentage. Based on the data when propane flow percentages are at $10 \%$ and $20 \%$, the concentration of $\mathrm{HCN}$ increases linearly as the current increases from 0.62 and $1.15 \mathrm{mg} / \mathrm{L}$ to 2.31 and $3.01 \mathrm{mg} / \mathrm{L}$, respectively. The reason is probably that the ionization degree of carrier gas increases as the current increases, and the amount of active 


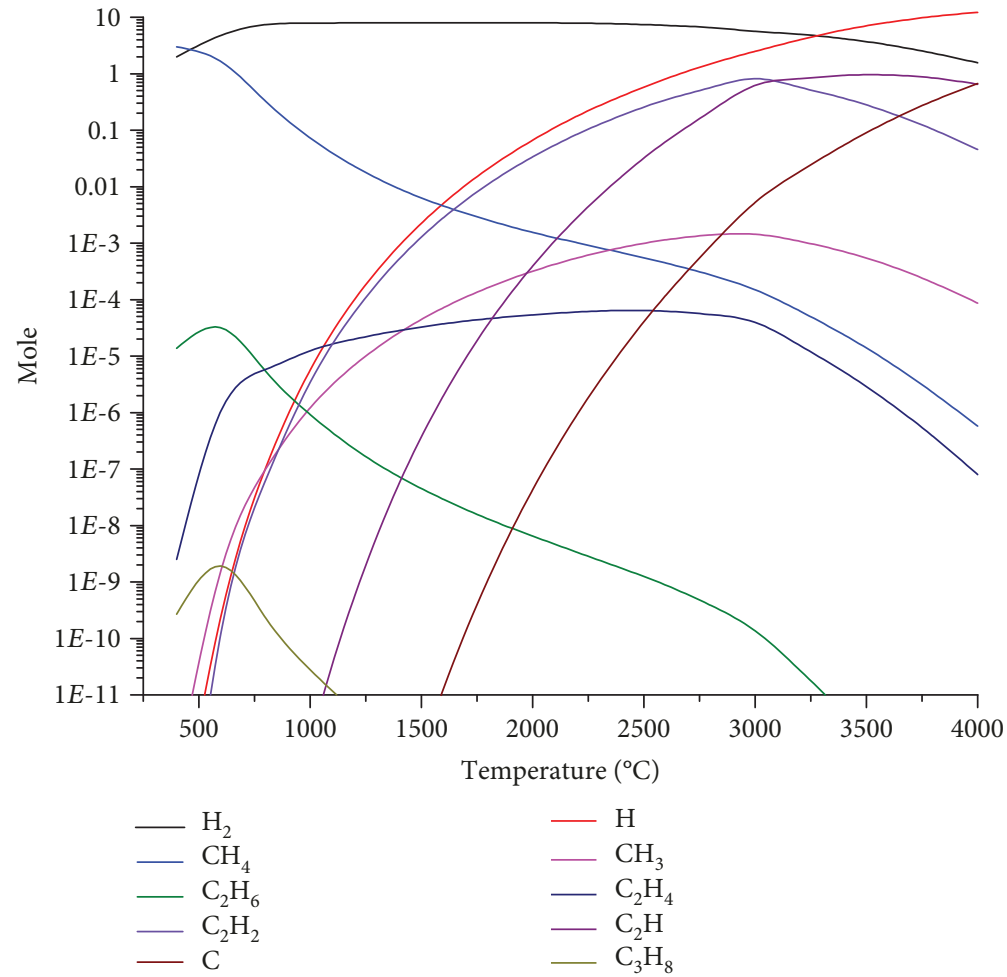

FIGURE 14: Simulated components of 1 mol propane after pyrolysis in argon under thermodynamic equilibrium.

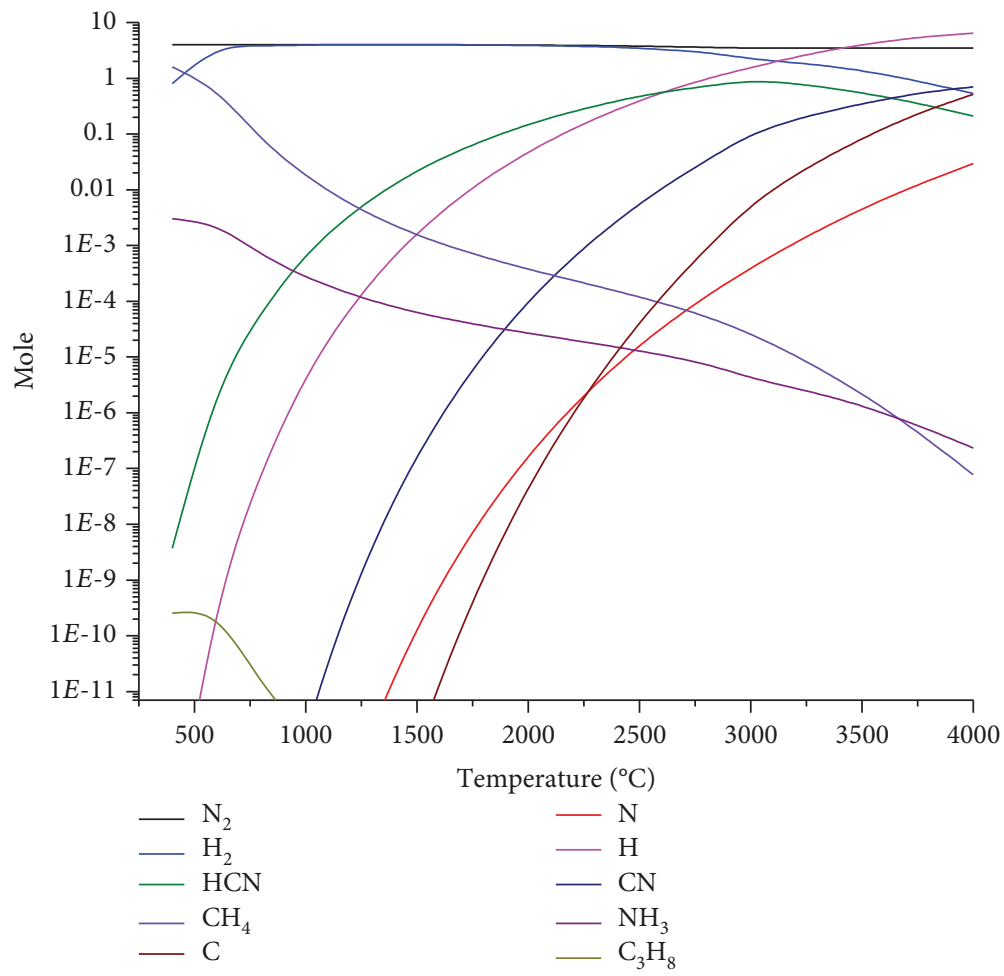

FIGURE 15: Simulated components of 1 mol propane after pyrolysis in nitrogen under thermodynamic equilibrium.

plasma species increases. Hence, the reaction system could obtain more heat, and the temperature of the system increased for the ease of propane pyrolysis. Therefore, many carbon and hydrogen radicals react with nitrogen radicals to generate $\mathrm{HCN}$ in the system. And the increase of temperature was conducive to the combination of the three species. 


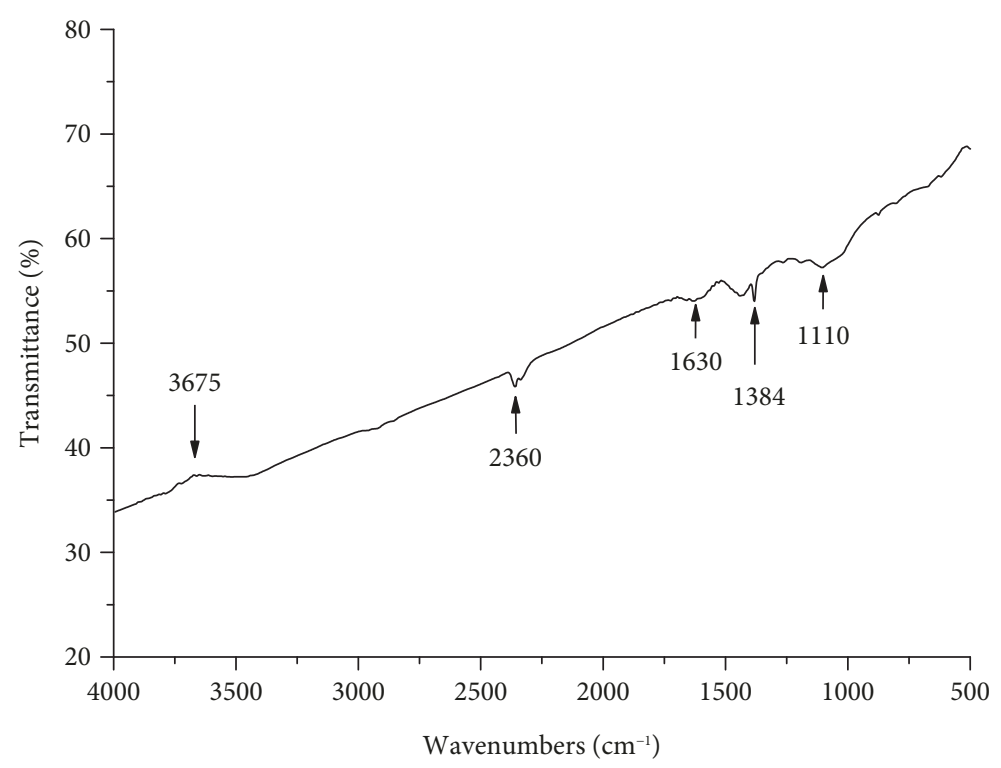

FIGURE 16: FT-IR spectrum of carbon black prepared using nitrogen.

When the propane flow percentage increases to $30 \%$ and the current in the range of $1 \mathrm{~A}$ to $3 \mathrm{~A}$, the concentration of $\mathrm{HCN}$ also increases linearly (from $1.85 \mathrm{mg} / \mathrm{L}$ to $3.58 \mathrm{mg} / \mathrm{L}$ ). However, when the current is further increased to $4 \mathrm{~A}$, the concentration of $\mathrm{HCN}$ becomes $3.61 \mathrm{mg} / \mathrm{L}$, which is almost the same as the results when the current is $3 \mathrm{~A}$. When the propane flow percentage is $30 \%$ and the current increases to some certain extent, the amount of carbon and hydrogen free radicals in the system is more than that of nitrogen. Further increasing of the current could not enhance the reaction extent to produce more $\mathrm{HCN}$. When the propane flow percentage increases to $40 \%$, the situation becomes more obvious. When the current is $2 \mathrm{~A}$, the reaction is nearly saturated, and the concentration of $\mathrm{HCN}$ reaches a plateau; when the currents are $3 \mathrm{~A}$ and $4 \mathrm{~A}$ and the propane flow percentage is $30 \%$, the concentration of $\mathrm{HCN}$ is low. The reason might be that when the propane flow percentage increases to $40 \%$, the amounts of carbon and hydrogen free radicals are high and the amount of nitrogen is low. Therefore, nitrogen combined less with carbon and hydrogen resulting in a decrease in concentration.

The experiments were also carried out to investigate the influence of the distance between electrodes $(1,2,3,4$, and $5 \mathrm{~mm}$ ) on the formation of HCN. Figure 13 illustrates the concentration of HCN absorbed in the sodium hydroxide from the tail gas at different distances between electrodes. The HCN concentration in the solution varies with distances between electrodes. When the distance is $1 \mathrm{~mm}$, the $\mathrm{HCN}$ concentration is as low as $1.19 \mathrm{mg} / \mathrm{L}$. The concentration increases with the increasing distance between electrodes. When the distance is increased to $3 \mathrm{~mm}$, the concentration reaches a peak value of $4.06 \mathrm{mg} / \mathrm{L}$ and started to decrease when the distance further increases. The HCN concentration decreases to $2.17 \mathrm{mg} / \mathrm{L}$ at a distance of $5 \mathrm{~mm}$. This is due to, at a $1 \mathrm{~mm}$ distance, the plasma volume being small and the electrodes too close to achieve the competition of reaction when mixed gases passed by, which leads to the low concentration of the byproduct HCN. The plasma volume increases with the increasing electrode distance, and the gas has sufficient time to react, resulting in increasing $\mathrm{HCN}$ concentration. However, after elongating the distance to more than $3 \mathrm{~mm}$, the current decreases and the plasma temperature is low. The energy of plasma is not enough to promote the pyrolysis of propane, and therefore, the concentration of $\mathrm{HCN}$ decreases again.

According to these experimental results, the amount of cyanide after the pyrolysis of $1 \mathrm{~mol}$ propane in nitrogen was calculated. For the sample prepared at an electrode distance of $3 \mathrm{~mm}$, a discharge current of $4 \mathrm{~A}$, and a propane percentage of $30 \%$, the amount of cyanide is $1.15 \times 10^{-4} \mathrm{~mol} / \mathrm{mol}$, which is lower than that from the thermodynamic equilibrium computation obtained between $1500^{\circ} \mathrm{C}$ and $2500^{\circ} \mathrm{C}$, the usual temperature range of $\mathrm{AC}$ arc discharge. This finding is due to the difficulty in reaching the thermodynamic equilibrium under experimental conditions and the insufficient reaction time for the formation of cyanide. Thus, carbon black was prepared at the electrode distance of $3 \mathrm{~mm}$, discharge current of $4 \mathrm{~A}$, and propane percentage of $30 \%$ under nitrogen plasma. The FT-IR and XPS measurements were further performed for more spectroscopic studies.

In the FT-IR spectrum, as shown in Figure 16, the peak at $3675 \mathrm{~cm}^{-1}$ is ascribed to $-\mathrm{OH}$ from water, which was adsorbed by carbon black in the air. The peak at $1384 \mathrm{~cm}^{-1}$ is due to the existence of the $\mathrm{C}-\mathrm{H}$ bending model. The peak at $1630 \mathrm{~cm}^{-1}$ originates from the stretching vibration of $\mathrm{C}=\mathrm{C}$, which is the essential unit of polycyclic aromatic hydrocarbon. In addition to the typical peaks in normal carbon black, two additional pattern peaks are also found in the spectrum. The peaks at $1110 \mathrm{~cm}^{-1}$ and $2360 \mathrm{~cm}^{-1}$ are assigned to the stretching vibration of $\mathrm{C}-\mathrm{N}$ and $\mathrm{C} \equiv \mathrm{N}$, respectively. The FT-IR results provide a solid evidence for the existence of cyanide. 


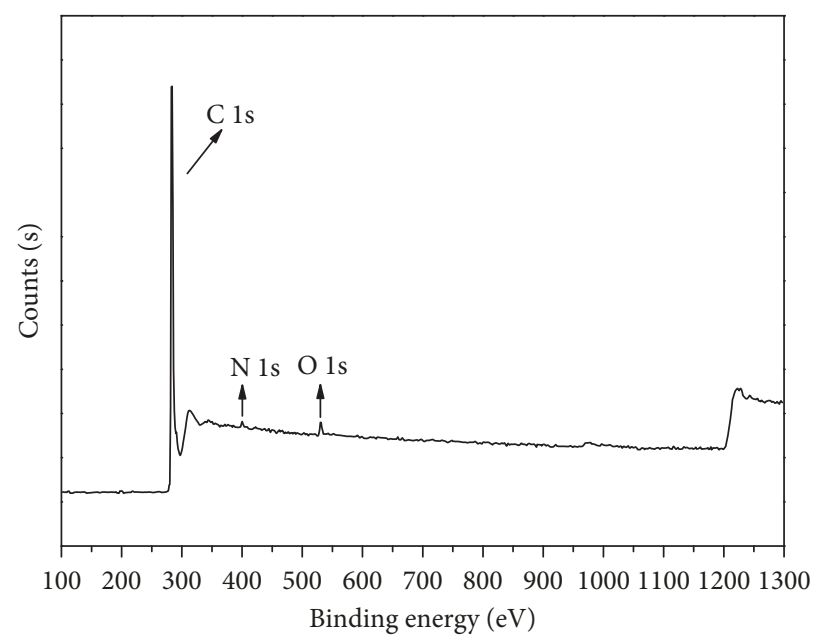

(a)

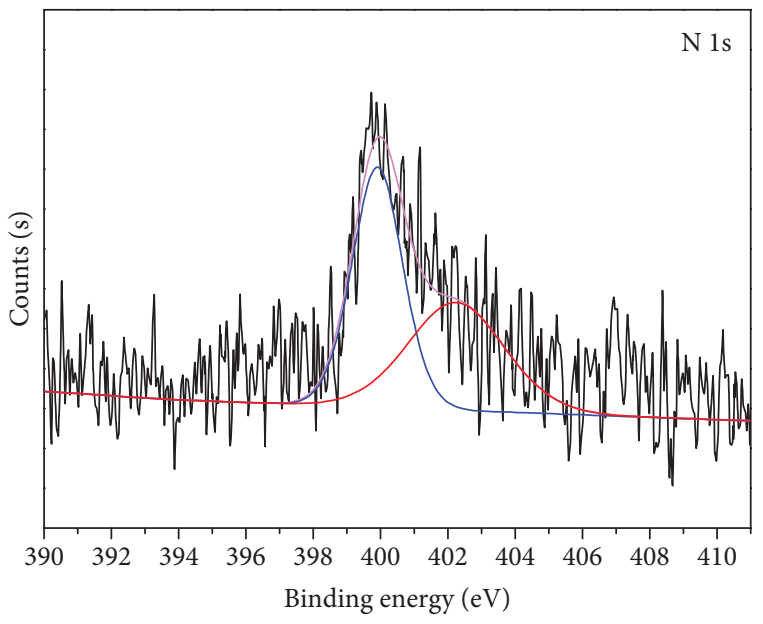

(b)

FIGURE 17: XPS of carbon black prepared using nitrogen.

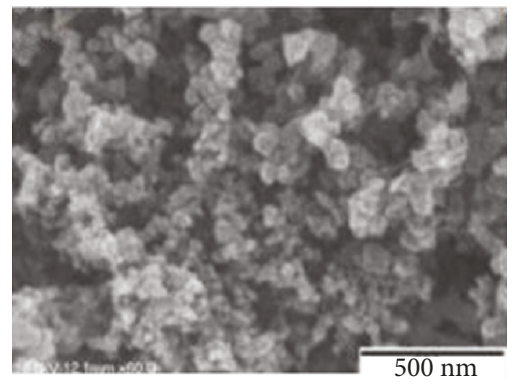

(a)

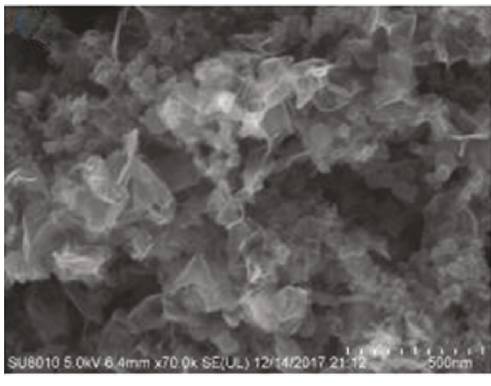

(b)

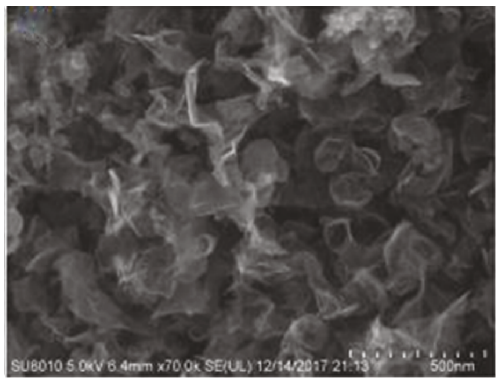

(c)

FIGURE 18: SEM of graphene prepared by plasma under different hydrogen/propane ratios: (a) without hydrogen, (b) $1: 40$, and (c) $1: 20$. All the scale bars are $500 \mathrm{~nm}$.

Figure 17 shows the XPS spectra of carbon black prepared from nitrogen plasma. The spectra reveal the existence of carbon, oxygen, and nitrogen bonds. The peaks around $284.6,400.0$, and $533.2 \mathrm{eV}$ represent $\mathrm{C}, \mathrm{N}$, and $\mathrm{O}$, respectively [47-49]. The existence of $\mathrm{O} 1 \mathrm{~s}$ suggests that the air in the reactor cannot be removed completely. The high resolution spectrum of $\mathrm{N} 1 \mathrm{~s}$ was further analyzed to acquire additional information about the chemical bonds on carbon black. Figure 17(b) shows the deconvoluted N 1s spectrum, which is fitted by two best fitted peaks with Gauss function. The peak at $399.6 \mathrm{eV}$ is attributed to the cyano group $-\mathrm{C} \equiv \mathrm{N}$, and the peak at $402.4 \mathrm{eV}$ is assignable to the pyridine group $\mathrm{C}-\mathrm{N}$ [50]. Although $\mathrm{O}$ has been detected, the $\mathrm{N}-\mathrm{O}$ bond is not found.

3.5. The Existence of Graphene in the Product. During the preparation of carbon black by pyrolysis of propane, it is remarkable to find the existence of graphene in the product, when using argon as plasma gas mixed with a small amount of hydrogen. As shown in Figure 18(a), only carbon black was observed in the range of vision with the absence of hydrogen. When a small amount of hydrogen (hydrogen/ propane ratio is $1: 40$ ) was added, some graphene appeared in the field of view, but the graphene boundary was blurred as shown in Figure 18(b). As the hydrogen flow ratio increases (hydrogen/propane ratio is $1: 20$ ), the amount of graphene in the field of view increases as shown in Figure 18(c), and the morphology of the graphene has distinct edge.

\section{Conclusions}

Carbon black was prepared by pyrolysis of propane using different plasma gases. The effects of plasma gases on the morphology and the structure of carbon black were investigated. We found that carbon black prepared by argon plasma exhibits the biggest particle size but the worst quality due to the deposition of abundant amorphous carbon. The carbon black prepared by hydrogen plasma shows the smallest particle size but the highest thermal stability because the surface is the cleanest. The carbon black prepared by nitrogen plasma exhibits the best quality. Unfortunately, $\mathrm{HCN}$ was found when using nitrogen as plasma gas by both the thermodynamics computations and the experimental investigations. The concentration of $\mathrm{HCN}$ increased with increasing current and amounts of propane but ceased to increase under certain 
current and propane content. At the same time, the distance between the electrodes also influenced the concentration of HCN. The presence of cyanide was confirmed by FT-IR and XPS analyses. The graphene could be found in the product when using argon as plasma gas with a small amount of hydrogen, and the content of graphene can be controlled by regulating the amount of hydrogen.

\section{Data Availability}

The data used to support the findings of this study are included within the article. Any more specific details on the data will be delivered by the corresponding author upon request.

\section{Disclosure}

The abstract of the submitted article had been presented at the 10th Annual Conference of China Particle Society and the Cross-Strait Particle Technology Seminar.

\section{Conflicts of Interest}

The authors declare that they do not have conflicts of interest.

\section{Acknowledgments}

This research was financially supported by the Foundation of Jiangsu Provincial Engineering Laboratory for Advanced Materials of Salt Chemical Industry (No. 82317070), the National Natural Science Foundation of China (NSFC, No. 21246002), the Minjiang Scholarship of Fujian Province, and the Central-Government Guided Special Funds for Local Economic Development (No. 830170778).

\section{References}

[1] J. Gonzalez-Aguilar, M. Moreno, and L. Fulcheri, "Carbon nanostructures production by gas-phase plasma processes at atmospheric pressure," Journal of Physics D: Applied Physics, vol. 40, no. 8, pp. 2361-2374, 2007.

[2] W. Cho, S.-H. Lee, W.-S. Ju, Y. Baek, and J. K. Lee, "Conversion of natural gas to hydrogen and carbon black by plasma and application of plasma carbon black," Catalysis Today, vol. 98, no. 4, pp. 633-638, 2004.

[3] E. Bormashenko, R. Pogreb, A. Musin, R. Balter, G. Whyman, and D. Aurbach, "Interfacial and conductive properties of liquid marbles coated with carbon black," Powder Technology, vol. 203, no. 3, pp. 529-533, 2010.

[4] J. Yan, T. Wei, B. Shao et al., "Electrochemical properties of graphene nanosheet/carbon black composites as electrodes for supercapacitors," Carbon, vol. 48, no. 6, pp. 17311737, 2010.

[5] M. S. Mauter and M. Elimelech, "Environmental applications of carbon-based nanomaterials," Environmental Science \& Technology, vol. 42, no. 16, pp. 5843-5859, 2008.

[6] F. Wang, R. Y. Hong, W. G. Feng, D. Badami, and K. Zeng, "Electrical and mechanical properties of ABS/EPDM composites filled with carbon black," Materials Letters, vol. 125, pp. $48-50,2014$.
[7] N. K. V. Nadimpalli, V. S. Buddhiraju, and V. Runkana, "Modeling and simulation of carbon black synthesis in an aerosol flame reactor," Advanced Powder Technology, vol. 22, no. 1, pp. 141-149, 2011.

[8] M. Ono-Ogasawara and T. Myojo, "Characteristics of multiwalled carbon nanotubes and background aerosols by carbon analysis; particle size and oxidation temperature," Advanced Powder Technology, vol. 24, no. 1, pp. 263-269, 2013.

[9] D. L. Sun, F. Wang, R. Y. Hong, and C. R. Xie, "Preparation of carbon black via arc discharge plasma enhanced by thermal pyrolysis," Diamond and Related Materials, vol. 61, pp. 2131, 2016.

[10] M. Inada, N. Enomoto, J. Hojo, and K. Hayashi, "Structural analysis and capacitive properties of carbon spheres prepared by hydrothermal carbonization," Advanced Powder Technology, vol. 28, no. 3, pp. 884-889, 2017.

[11] Y. B. Fainberg, "Plasma electronics and plasma methods of charged particle acceleration," Plasma Physics Reports, vol. 20, pp. 549-554, 1994.

[12] L. Bromberg, D. R. Cohn, A. Rabinovich et al., Onboard Plasmatron Hydrogen Production for Improved Vehicles, Massachusetts institute of Technology MIT Plasma Science and Fushion Center, 2006.

[13] T. Kappes, W. Schiene, and T. Hammer, "Energy balance of a dielectric barrier discharge reactor for hydrocarbon steam reforming," in 8th International Symposium on High Pressure Low Temperature Plasma Chemestry proceedings, p. 49, Hakone, Japan, 2002.

[14] T. Paulmier and L. Fulcheri, "Use of non-thermal plasma for hydrocarbon reforming," Chemical Engineering Journal, vol. 106, no. 1, pp. 59-71, 2005.

[15] J. M. Cormier and I. Rusu, "Syngas production via methane steam reforming with oxygen: plasma reactors versus chemical reactors," Journal of Physics D: Applied Physics, vol. 34, no. 18, pp. 2798-2803, 2001.

[16] M. Sobacchi, A. Saveliev, A. Fridman, L. A. Kennedy, S. Ahmed, and T. Krause, "Experimental assessment of a combined plasma/catalytic system for hydrogen production via partial oxidation of hydrocarbon fuels," International Journal of Hydrogen Energy, vol. 27, no. 6, pp. 635-642, 2002.

[17] L. A. Arce-Saldaña, E. Espinoza-Mosso, B. Castro-Rodríguez et al., "Plasma synthesis of carbon powder with embedded $\mathrm{Fe}_{3} \mathrm{C}$ nanoparticles for magnetic separation of biomolecules," Advanced Powder Technology, vol. 29, no. 4, pp. 10351041, 2018.

[18] V. D. Rusanov, A. I. Babaritskii, E. N. Gerasimov et al., "Stimulation of the partial oxidation of methane in a microwave discharge," Doklady Physics, vol. 48, no. 3, pp. 119-122, 2003.

[19] A. I. Babaritskii, I. E. Baranov, M. B. Bibikov et al., "Partial hydrocarbon oxidation processes induced by atmosphericpressure microwave-discharge plasma," High Energy Chemistry, vol. 38, no. 6, pp. 407-411, 2004.

[20] S. Asai, Y. Sekine, K. Urasaki, E. Kikuchi, M. Matsukata, and S. Kado, "Development of liquid fuel reformer using low energy pulse (LEP) discharge at room temperature," in Asian Pacific Confederation of Chemical Engineering Congress Program, pp. 255-255, 2004.

[21] F. Fabry, G. Flamant, and L. Fulcheri, "Carbon black processing by thermal plasma. Analysis of the particle formation mechanism," Chemical Engineering Science, vol. 56, no. 6, pp. 2123-2132, 2001. 
[22] G. Petitpas, J.-D. Rollier, A. Darmon, J. Gonzalez-Aguilar, R. Metkemeijer, and L. Fulcheria, "A comparative study of non-thermal plasma assisted reforming technologies," International Journal of Hydrogen Energy, vol. 32, no. 14, pp. 28482867, 2007.

[23] J. R. Rose, "Process of and apparatus for producing carbon and gaseous fuel," 1920, US Patent US3420632.

[24] N. W. Ryan, "Production of carbon black using plasma-heated nitrogen,” 1969, US Patent US3420632.

[25] M. K. Nikoo and N. A. S. Amin, “Thermodynamic analysis of carbon dioxide reforming of methane in view of solid carbon formation," Fuel Processing Technology, vol. 92, no. 3, pp. 678-691, 2011.

[26] R. Hong, Z. Ren, J. Ding, and H. Li, "Experimental investigation and particle dynamic simulation for synthesizing titania nanoparticles using diffusion flame," Chemical Engineering Journal, vol. 108, no. 3, pp. 203-212, 2005.

[27] L. Chen, R. Y. Hong, and H. Li, "Thermodynamic investigation of plasma pyrolysis of hydrocarbon," Computers and Applied Chemistry, vol. 24, no. 6, 2007.

[28] F. Wang, D. L. Sun, R. Y. Hong, and M. R. Kumar, "Preparation of carbon nanoparticles by plasma arc discharge under fluidized dynamic equilibrium," Journal of Nanoparticle Research, vol. 18, no. 6, 2016.

[29] D. Bittner, H. Baumann, and J. Klein, "Relation between coal properties and acetylene yield in plasma pyrolysis," Fuel, vol. 64 , no. 10 , pp. 1370-1374, 1985.

[30] J. C. Pereira-Lima, J. V. Busnello, C. Saul et al., "High power setting argon plasma coagulation for the eradication of Barrett's esophagus," American Journal of Gastroenterology, vol. 95, no. 7, pp. 1661-1668, 2000.

[31] B. Yan, P. Xu, C. Y. Guo, Y. Jin, and Y. Cheng, "Experimental study on coal pyrolysis to acetylene in thermal plasma reactors," Chemical Engineering Journal, vol. 207-208, pp. 109116, 2012.

[32] X. Y. Liu, R. Y. Hong, W. G. Feng, and D. Badami, "Synthesis of structure controlled carbon nanomaterials by AC arc plasma process," Powder Technology, vol. 256, pp. 158165, 2014.

[33] S. Zhao, R. Hong, Z. Luo, H. Lu, and B. Yan, "Carbon nanostructures production by AC arc discharge plasma process at atmospheric pressure," Nanomaterials, vol. 2011, Article ID 346206, 6 pages, 2011.

[34] W. Zhang and Y. Catherine, "Deposition of carbon films by the dissociation of methane in r.f. discharge," Surface and Coatings Technology, vol. 47, no. 1-3, pp. 69-83, 1991.

[35] C. R. Houska and B. E. Warren, "X-ray study of the graphitization of carbon black," Journal of Applied Physics, vol. 25, no. 12, pp. 1503-1509, 1954.

[36] B. R. Locke, M. Sato, P. Sunka, M. R. Hoffmann, and J. S. Chang, "Electrohydraulic discharge and nonthermal plasma for water treatment," Industrial and Engineering Chemistry Research, vol. 45, no. 3, pp. 882-905, 2006.

[37] R. Saito, G. Dresselhaus, and M. S. Dresselhaus, "Physical Properties of Carbon Nanotubes," in World Scientific Publishing Company, 1998.

[38] K.-J. Cho, J.-T. Ryu, Y.-G. Baek et al., "Fabrication and characteristics of amorphous carbon films grown in pure methane plasma by using radio frequency plasma enhanced chemical vapor deposition," Journal of Applied Physics, vol. 42, Part 1, pp. 1744-1748, 2003.
[39] M. Kumar and Y. Ando, "Single-wall and multi-wall carbon nanotubes from camphor-a botanical hydrocarbon," Diamond and Related Materials, vol. 12, no. 10-11, pp. 1845-1850, 2003.

[40] A. R. Bunsell, "Fibre reinforcements for composite materials and electron microscopy," Microscopy Microanalysis Microstructures, vol. 2, no. 1, pp. 1-13, 1991.

[41] Y. Lin, T. W. Smith, and P. Alexandridis, "Adsorption of a rake-type siloxane surfactant onto carbon black nanoparticles dispersed in aqueous media," Langmuir, vol. 18, no. 16, pp. 6147-6158, 2002.

[42] L. Xie, L. Jiao, and H. Dai, "Selective etching of graphene edges by hydrogen plasma," Journal of the American Chemical Society, vol. 132, no. 42, pp. 14751-14753, 2010.

[43] K. Nakamura, M. Fujitsuka, and M. Kitajima, "Disorderinduced line broadening in first-order Raman scattering from graphite," Physical Review B, vol. 41, no. 17, pp. 12260 12263, 1990.

[44] W. Li, H. Zhang, C. Wang et al., "Raman characterization of aligned carbon nanotubes produced by thermal decomposition of hydrocarbon vapor," Applied Physics Letters, vol. 70, no. 20, pp. 2684-2686, 1997.

[45] X. B. Ai, H. Bai, L. H. Zhao, D. Q. Cang, and Q. Tang, "Thermodynamic analysis and formula optimization of steel slag-based ceramic materials by FACTsage software," International Journal of Minerals, Metallurgy, and Materials, vol. 20, no. 4, pp. 379-385, 2013.

[46] L. Fulcheri, N. Probst, G. Flamant, F. Fabry, E. Grivei, and X. Bourrat, "Plasma processing: a step towards the production of new grades of carbon black," Carbon, vol. 40, no. 2, pp. 169176, 2002.

[47] H. Estrade-Szwarckopf, "XPS photoemission in carbonaceous materials: a "defect" peak beside the graphitic asymmetric peak," Carbon, vol. 42, no. 8-9, pp. 1713-1721, 2004.

[48] S. Biniak, G. Szymański, J. Siedlewski, and A. Światkowski, "The characterization of activated carbons with oxygen and nitrogen surface groups," Carbon, vol. 35, no. 12, pp. 17991810, 1997.

[49] X. C. LeQuan, W. P. Kang, J. L. Davidson, M. Guo, and B. K. Choi, "Micro-Raman, SEM, XPS, and electron field emission characterizations of nitrogen-induced shallow defects on nanodiamond films fabricated with different growth parameters," Diamond and Related Materials, vol. 18, no. 2-3, pp. 191-195, 2009.

[50] R. J. J. Jansen and H. van Bekkum, "XPS of nitrogencontaining functional groups on activated carbon," Carbon, vol. 33, no. 8, pp. 1021-1027, 1995. 


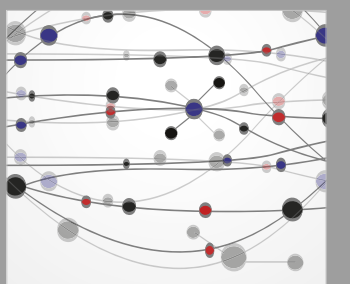

The Scientific World Journal
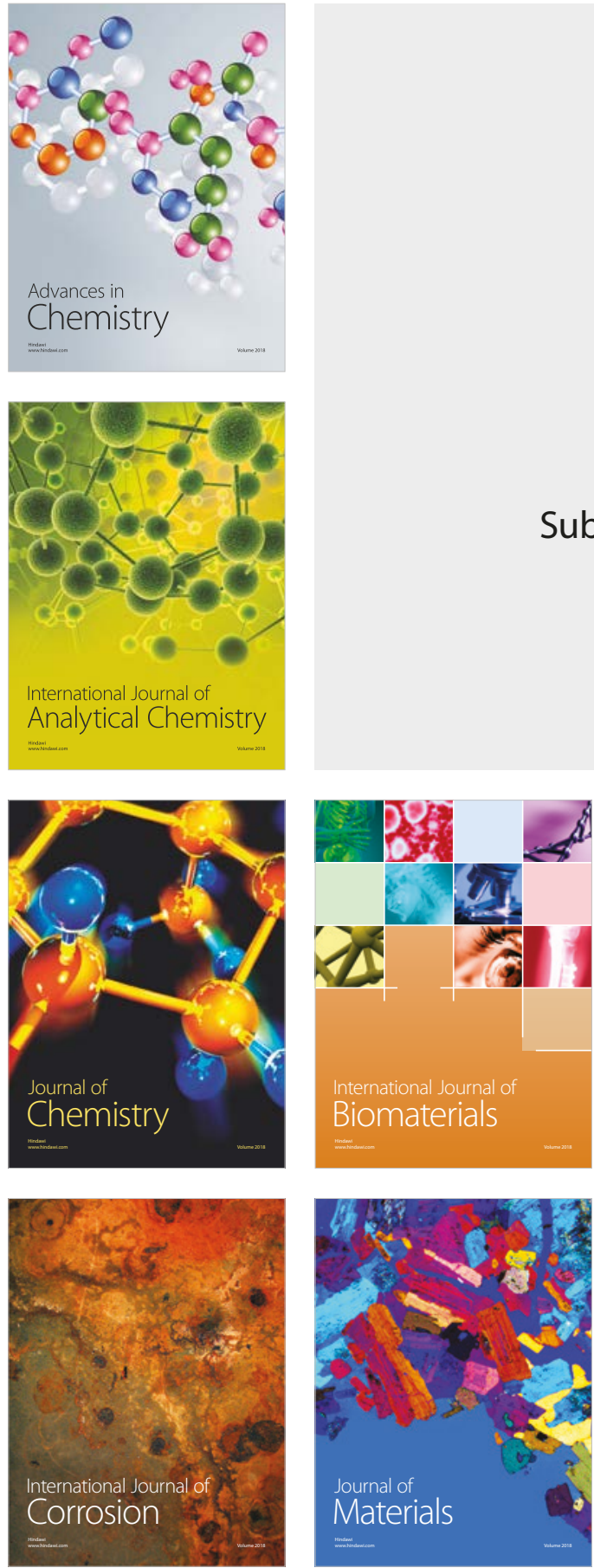

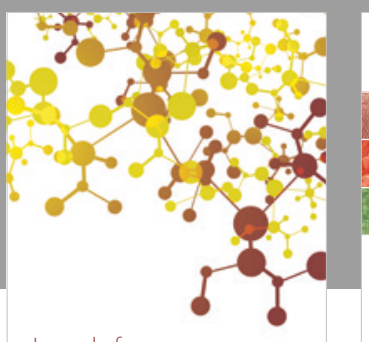

Journal of

Applied Chemistry
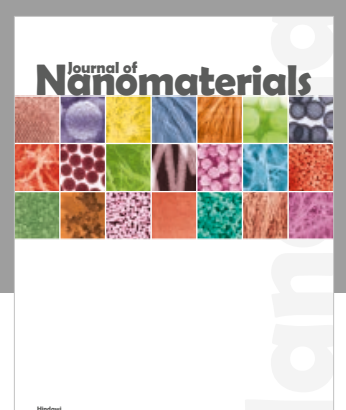

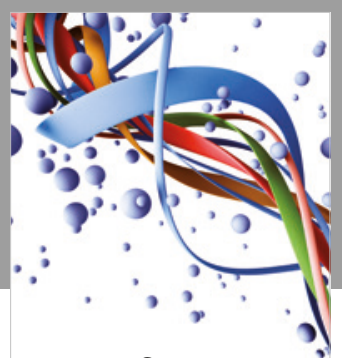

Scientifica

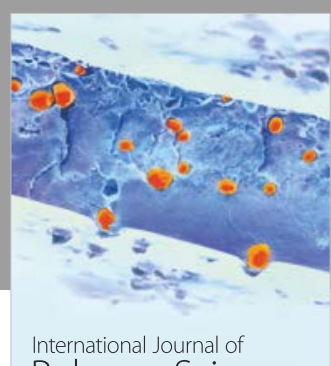

Polymer Science

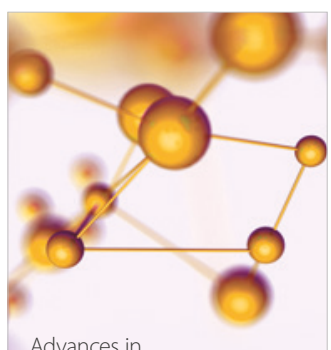

Physical Chemistry
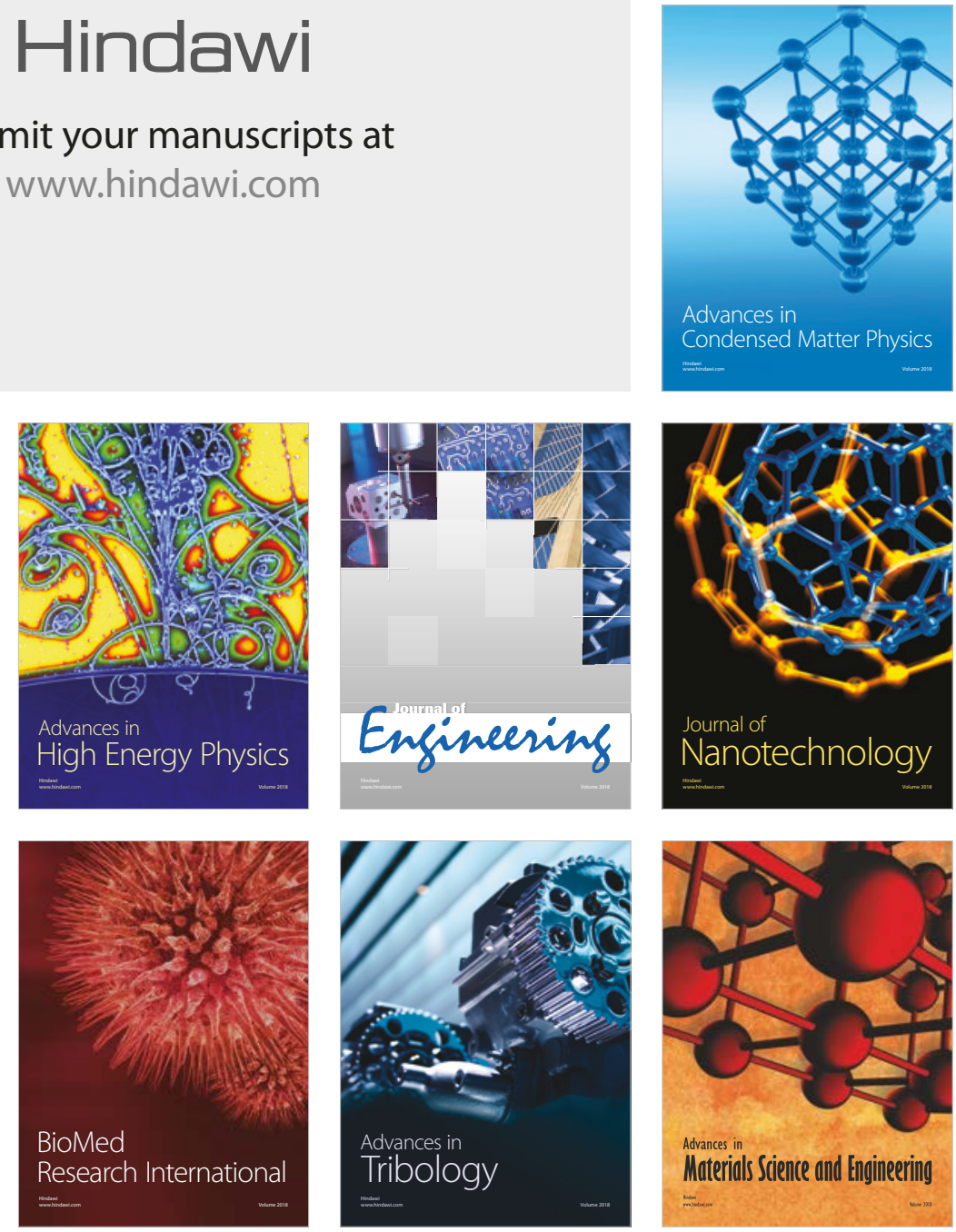